\title{
Climate-panel chief Hoesung Lee wants focus on solutions
}

\section{The newly elected chairman of the Intergovernmental Panel on Climate Change outlines his philosophy.}

\section{Jeff Tollefson}

13 October 2015

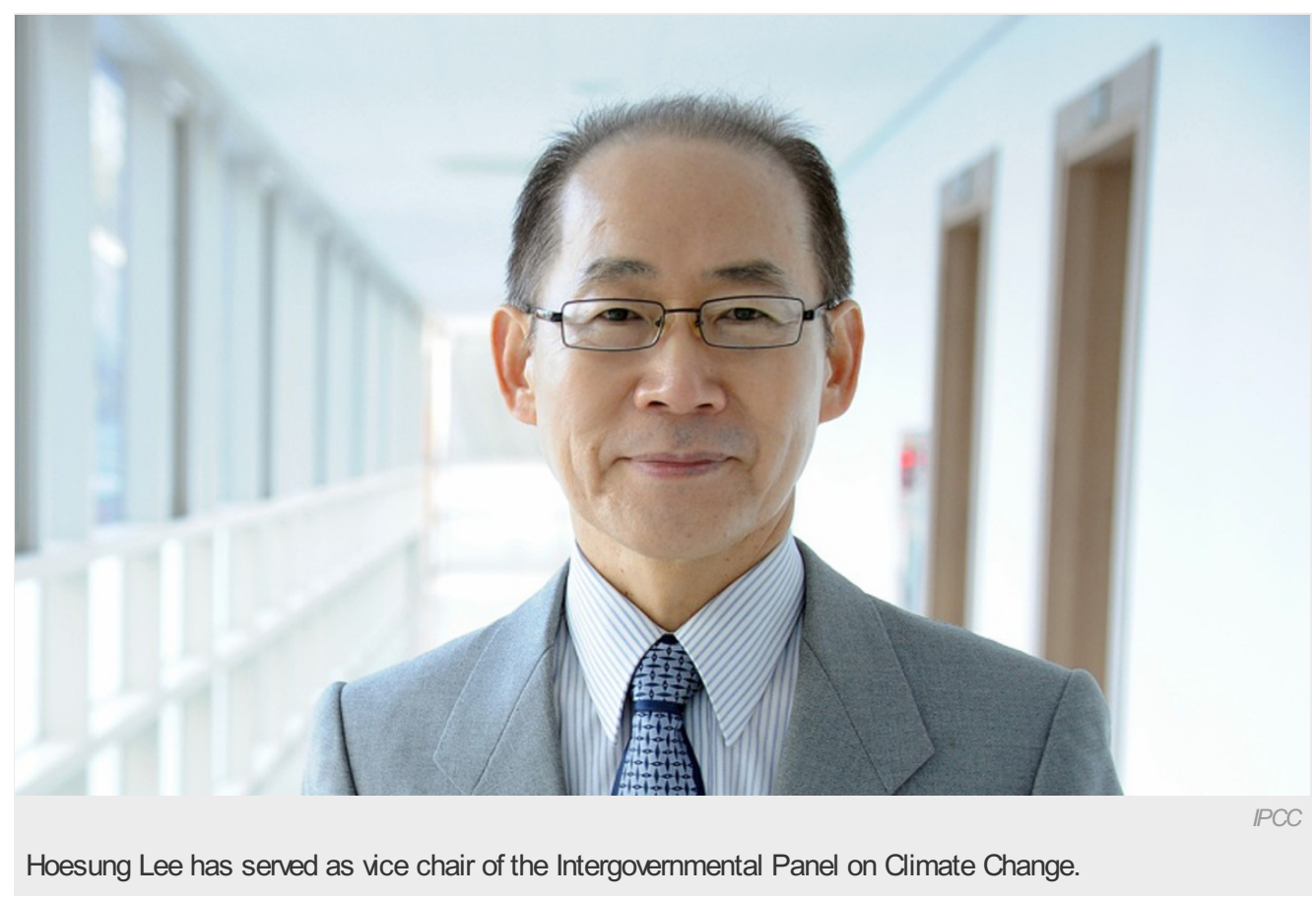

South Korean economist Hoesung Lee was elected as the fourth chairman of the Intergovernmental Panel on Climate Change (IPCC) on 6 October. He will lead the panel through its sixth major assessment of climate-change science, impacts and solutions. Lee, at Korea University in Seoul, says that he has developed a deep understanding of the climate panel since he began participating in 1992.

Nature talks to Lee about his plans and hopes for the IPCC. This interview has been edited for length and clarity.

\section{What changes do you plan to make to IPCC structures and procedures?}

I look forward to improving coordination among the three working groups. This will improve the efficiency of writing the synthesis report and above all make it more meaningful. There are also opportunities to streamline and upgrade our administrative processes so as to lessen the burden on our workers. Our process needs to be more bottom-up and inclusive.

We need to continue to improve how we communicate. Our reports have to be understandable. I support the idea to induct professional science writers and graphics experts into the working groups. We still need to consider this proposal. I also intend to increase our outreach activities, especially to business and finance.

Some say that the IPCC should produce shorter assessments and focus more energy on rapid special reports. What do you think?

Since 2010, we have published more than a dozen reports of varying length and depth. Whether we should focus more energy on rapid special reports really depends on financial resources and also the constraints of intellectual manpower. We need to give more thought to that.

\section{How will you bridge the divide between the developed and developing world?}

I grew up in a country impoverished by war, and I experienced later how we recovered and grew through separate stages of development, including a growing awareness of the need to protect the environment. This has given me a very personal understanding of the differences and similarities between developing, developed and transition economies. That gives me a very valuable insight that will be very, very useful in working with delegates from all around the world. 


\section{How do you plan to involve more scientists from developing countries?}

We need to identify and communicate with local centres of excellence in areas of climate science, adaptation and mitigation as well as in disciplines related to economic development and poverty reduction. We also need to train promising young scholars from developing countries. We need to approach this goal of improving scientists from developing countries in a more systematic way.

\section{You've said that you want to engage the business, industrial and financial sectors. Why is that important?}

They have the resources, they have the information, they have the knowledge, and we will benefit greatly by capitalizing on their intellectual basis. We will increase the interactions with business and financial sectors through our outreach activities.

Some have called for increased transparency in the IPCC process, including allowing social scientists to study the panel. What is your position on this issue?

It's very important to recognize that the IPCC has improved its transparency. We have greatly enhanced our communications programme and will continue to make improvements along those lines so that the world has great and easy access to understandable information. There are more than 100 intergovernmental organizations, non-governmental organizations, observer organizations and United Nations' entities that attend our plenary sessions.

We have already started the process of allowing social scientists to study the organization. This is another major step toward increasing the transparency and understanding of the organization.

\section{What about granting media access?}

I know that there has been such a request. I'm not in a position at this time to make any comment. That decision rests with the whole panel.

You have called for greater policy relevance and neutrality. Do you think that former chairman Rajendra Pachauri veered too far into policy advocacy, as some have argued?

I leave it to others to answer this question. We have been very keen in maintaining policy relevance without being policy prescriptive. We need to continue to emphasize our role as an objective comprehensive scientific assessment body. That's the reason I emphasize this policy neutrality.

\section{What do you hope your legacy will be?}

I would like to be remembered as the chairman that shifted the IPCC's focus to solutions. We have the knowledge and the technology not only to tackle climate change but also to build a much more prosperous and equitable society in this process. There's a great deal to be concerned about, but there is also a great deal to be excited about.

Nature | doi:10.1038/nature.2015.18556 